\title{
BMJ Open Identifying priority medicines policy issues for New Zealand: a general inductive study
}

\author{
Zaheer-Ud-Din Babar, Susan Francis
}

To cite: Babar Z-U-D, Francis S. Identifying priority medicines policy issues for New Zealand: a general inductive study. BMJ Open 2014:4:e004415.

doi:10.1136/bmjopen-2013004415

- Prepublication history and additional material is available. To view please visit the journal (http://dx.doi.org/ 10.1136/bmjopen-2013004415).

Received 6 November 2013

Revised 17 April 2014

Accepted 6 May 2014

CrossMark

Faculty of Medical and Health Sciences, School of Pharmacy, University of Auckland, Auckland, New Zealand

Correspondence to Dr Zaheer-Ud-Din Babar; z.babar@auckland.ac.nz

\section{ABSTRACT}

Objectives: To identify priority medicines policy issues for New Zealand.

Setting: Stakeholders from a broad range of healthcare and policy institutions including primary, secondary and tertiary care.

Participants: Exploratory, semistructured interviews were conducted with 20 stakeholders throughout New Zealand.

Primary and secondary outcome measures:

The interviews were digitally recorded, transcribed and coded into INVIVO 10, then compared and grouped for similarity of theme. Perceptions, experiences and opinions regarding New Zealand's medicines policy issues were recorded.

Results: A large proportion of stakeholders appeared to be unaware of New Zealand's (NZ) medicines policy. In general, the policy was considered to offer consistency to guide decision-making. In the context of Pharmaceutical Management Agency's (PHARMAC's) fixed budget for procuring and subsidising medicines, there was reasonable satisfaction with the range of medicines available - rare disorder medicines being the clear exception. Concerns raised were by whom and how decisions are made and whether desired health outcomes are being measured. Other concerns included inconsistencies in evidence and across health technologies. Despite attempts to improve the situation, lower socioeconomic groups (including rural residents) Māori and Pacific ethnicities and people with rare disorders face challenges with regards to accessing medicines. Other barriers include, convenience to and affordability of prescribers and the increase of prescription fees from NZ\$3 to NZ\$5. Concerns related to the PHARMAC of New Zealand included: a constraining budget; non-transparency of in-house analysis; lack of consistency in recommendations between the Pharmacology and Therapeutics Advisory Committee. Constraints and inefficiencies also exist in the submission process to access high-cost medicines. Conclusions: The results suggest reasonable satisfaction with the availability of subsidised medicines. However, some of the major challenges include access to medicines in vulnerable groups, increasing costs and demand for new medicines, access to prescribers, budgetary constraints, cultural and health literacy, patient affordability and evidence requirement for gaining subsidy for medicines.

\section{Strengths and limitations of this study}

- This study is the first independent objective study to identify priority medicines policy issues, from a broad range of stakeholders.

- Has identified access to medicine issues requiring further research.

- Provides a context to identify issues.

- The views expressed are from 20 stakeholders. Issues raised in this research project are therefore indicative.

\section{INTRODUCTION}

New Zealand has a population of approximately 4.5 million, with a nominal gross domestic product of approximately NZ\$211 billion. ${ }^{1}$ New Zealanders have an average life expectancy of 81.2 years, which is above the Organisation for Economic Co-operation and Development (OECD) countries' average of 80.1 years. ${ }^{2}$ Just under $83 \%(82.7 \%)$ of health expenditure in New Zealand is publicly funded. ${ }^{3}$ New Zealand's health and disability budget at the starting of this research is NZ $\$ 13.983$ billion. $^{3}$ In comparison with other OECD countries, as a percentage of total expenditure on health, New Zealand spends less on pharmaceuticals. ${ }^{2}$ Approximately NZ $\$ 795$ million and NZ\$280 million are available for procuring community/cancer and hospital pharmaceuticals, respectively. ${ }^{4}$ This compares with a reported estimated spend of NZ\$880 million on medical devices. ${ }^{5}$ Approximately 1848 medicines are subsidised by Pharmaceutical Management Agency (PHARMAC, as listed on its Pharmaceutical Schedule) for use in the community and are largely accessible via prescription from a medical doctor. ${ }^{6}$

\section{Medicines and New Zealand}

Medicines make a significant contribution to health outcomes. ${ }^{7}$ In 2007, 'Medicines New Zealand' New Zealand's medicines policy, was launched in response to access 
concerns from the public. ${ }^{7}$ The aim of the policy is to promote quality, effective and optimally used medicines. To guide decisions, principles of affordability, equity and need are stated. ${ }^{7}$ Medicines New Zealand aims to ensure that the decisions made about prioritisation and funding are as transparent as possible, understood and open to debate. It is important for New Zealanders to have confidence that the medicines system is fair, even if they do not always agree with the decisions made. ${ }^{7}$

\section{Pharmaceutical Management Agency}

PHARMAC, established in 1993 in response to increasing expenditure on pharmaceuticals, is a separate nonprofit government agency whose role is to determine and procure community and oncology medicines on behalf of New Zealand's 20 District Health Boards (DHBs). PHARMAC has a predetermined fixed budget which it is required to operate within. In order to provide medicines considered necessary, PHARMAC employs therapeutic and economic analyses to guide decisions. PHARMAC's scope is now expanding to include hospital medicines and some medical devices.

For the majority of patients prescribed a medicine listed on PHARMAC's schedule, a NZ\$5 DHB charge is incurred. For high user or low socioeconomic patients, access enablers (eg, Prescription Subsidy, Community Services and High User cards and, recently, the Services to Improve Access (SIA)) exist to help ease the financial burden. ${ }^{6}$

Literature exists indicating medicine issues for $\mathrm{New}$ Zealand related to: inequities in access, affordability, processes used and their funding. ${ }^{8-31}$ However, no systematic work has been conducted to identify priority medicines policy issues with regard to access and funding of medicines. Within this context, it was considered timely and appropriate to conduct research that could identify priority medicines policy issues for New Zealand.

The dataset obtained from this research was expected to be substantial and provide a solid platform to contribute towards informing medicines policy, expenditure and provision, and the development of optimal medicines management strategies.

\section{Aim}

The aim of this project was to identify priority medicines policy issues for New Zealand.

\section{METHODS}

\section{Study design and participant selection}

We conducted a general inductive study using semistructured exploratory interviews during December 2012March 2013. Selection was purposeful to ensure a broad representation of stakeholders and their opinions, who had one or more of the following traits in relation to medicines policy: involvement in its formation or implementation had researched and/or commented on medicines policy, including having made submissions during its development $(\mathrm{n}=10)$; medically qualified doctor $(\mathrm{n}=7$, four of whom were active prescribers, including one of each of Māori, Indian and Asian ethnicity); medicines regulation $(n=1)$; representation of or past or current involvement in medicines supply, procurement, funding or provision (excluding dispensing, $n=6$ ); involved in medicines management $(n=9$, one of whom was of Māori ethnicity); medical information or health technology assessment interest $(n=2)$; medical interest group representative (includes ethnic medical group/ association, past or present, $n=4)$; private health provision and subsidy $(\mathrm{n}=1)$; patient group representative (PGR; $\mathrm{n}=2$, one of whom represents and advocates for a large chronic disease group, disproportionately represented by Māori, Pacifica and increasingly Indian and Asian ethnicity). Participants' characteristics are summarised in table 1.

A total of 26 stakeholders were contacted and explained the research involvement. Twenty stakeholders consented and were interviewed. All 20 received a 'Participants Information' letter detailing the involvement, aim and general methods. All signed a confidentiality and anonymity agreement. Fifteen interviews were conducted face to face and five via telephone, due to geographical or time

Table 1 Stakeholder characteristics: stakeholders $\mathrm{n}=20$

\begin{tabular}{|c|c|c|}
\hline Stakeholder & Number & Comments \\
\hline Academia (A) & 3 & $\begin{array}{l}\text { Sociologists (2), } \\
\text { Pharmacoeconomist (1) }\end{array}$ \\
\hline Public service (PS) & 5 & $\begin{array}{l}\text { Politician (1), Medsafe (1), } \\
\text { Policy analyst (1), DHB } \\
\text { planning (1), Pharmac (1) }\end{array}$ \\
\hline Medicine (M) & 4 & $\begin{array}{l}\text { Oncologist (1), General } \\
\text { practice (3) }\end{array}$ \\
\hline Pharmacist (Ph) & 3 & DHB (2), Community (1) \\
\hline $\begin{array}{l}\text { Pharmaceutical } \\
\text { industry (PI) }\end{array}$ & 2 & $\begin{array}{l}\text { Manufacturing (1), } \\
\text { Representative (1) }\end{array}$ \\
\hline $\begin{array}{l}\text { Patient Group } \\
\text { Representative } \\
\text { (PGR) }\end{array}$ & 2 & Long-term conditions (2) \\
\hline $\begin{array}{l}\text { Private Health } \\
\text { Care Organisation } \\
\text { (PHCO) } \\
\text { Additional attributes }\end{array}$ & f stakeholc & Medical doctor (1) \\
\hline $\begin{array}{l}\text { - } 3 \text { Medically qualific } \\
\text { doctors } \\
\text { 1 Pharmacist }\end{array}$ & & $\begin{array}{l}1 \text { Health professional } \\
\text { of Māori ethnicity } \\
4 \text { Doctors' past or } \\
\text { current medical group } \\
\text { representation }\end{array}$ \\
\hline - 3 Scientists & & $\begin{array}{l}3 \text { GPs' ethnicities: } \\
\text { Māori, Indian and } \\
\text { Asian; past or currently } \\
\text { practising in areas with } \\
\text { high numbers of } \\
\text { respective ethnicity, } \\
\text { including Pacifica }\end{array}$ \\
\hline \multicolumn{3}{|c|}{$\begin{array}{l}\text { 1 } 1 \text { Medical IT } \\
1 \text { Therapeutic assessor }\end{array}$} \\
\hline
\end{tabular}


constraints. The average length of the interview ranged from 53 to $56 \mathrm{~min}$. No gratuity was offered.

\section{Instrument development}

The main aim of this research was to identify priority medicines policy areas. An in-depth literature review was conducted to ascertain existing information on pharmaceutical policy. A total of 105 references were identified as useful. The following broad themes were discovered and, accordingly, sets of questions developed: (1) medicines policy: including participant's awareness, description and opinions; (2) ethnicity inequities in accessing medicines (eg, Māori, Pacifica and recently immigrated people whose first language was not English); (3) PHARMAC: its pricing policy, impact on access, economic modelling, performance, future and any improvements; (4) the Trans Pacific Partnership Agreement (TPPA): impact on access and resultant considerations; (5) highcost medicines access; and (6) medicines policy issues not covered but considered important (see online supplementary appendix one for question details).

The questions were piloted by one doctor of Māori ethnicity and one pharmacist $(\mathrm{Ph})$ with an interest in medicines policy, medicines management and academia, who had previous experience in the pharmaceutical industry. Their responses were not included for analysis.

\section{Data collection}

Participants (stakeholders) were encouraged to give comprehensive answers. Clarifying and confirming questions were asked where more information was considered necessary, or to avoid interviewer assumption.

All interviews were recorded on a voice recorder, and transcribed intelligently (space fillers were omitted to enable ease of reading). Participants received their own transcript to proof, edit and approve. Only the approved editions were entered into INVIVO 10 (QSR International Pty Ltd) for coding.

Coding was conducted two ways: first, categorically according to answers and second, highlighted, grouped and compared according to similarity of theme. Transcripts were checked for any missed issues.

A check for stakeholder bias was conducted using the coding summaries, but no apparent bias was detected. Any variations appeared to be attributable to stakeholder knowledge.

\section{RESULTS}

Issues revealed specific to ethnicity, PHARMAC, the TPPA or high-cost medicines are reported in those sections. A summary of issues is available in table 2.

\section{General medicines policy issues}

Nine participants stated they were unfamiliar with the policy. However, four demonstrated a tacit understanding. It was questioned how policy intentions and decisions are made, in the context of being achievable:
How do you attain that?...what is the right way to make those overall policy decisions... (pharmaceutical industry stakeholder, PI)

All participants believed medicines make a positive contribution to health. Differing levels of impact on health were noted. There was uncertainty as to how the impact is or could be quantified. The lost opportunity from not capturing and accessing data efficiently was voiced by two academics for treatment and outcomes monitoring:

...we are not asking questions about patient health status before and after...so you can really see what is going on, at the GP level. Because that's at least as important as hospitalisation data (Academic, Ac)

Conversely, one participant said he would prefer to see more investment in epidemiology, as opposed to increasing the medicines budget, in a desire to preserve health.

Low socioeconomic patients were considered to have a higher burden of disease. Affordability to prescribers was described as the major issue, which may be compounded by the 2013 raise in prescription copayment from NZ\$3 to NZ\$5.

Despite access enablers, such as the High User Cards and Community Services Cards, it was questioned whether those in need are utilising them. One general practitioner (GP) said cost-sensitive patients could be managed with prudent prescribing and education on priorities:

You could get all your medicines for less than a pack of cigarettes. It's educational priorities and various other things, where the effort needs to go rather than reducing the cost much further (GP)

The opposite situation of the misuse of access was described:

I initially struggled to understand how somebody could pull up outside a pharmacy in a Mercedes Benz and... present their scripts for their family and handover their Community Services Card...As soon as they get in the country; they put the money into a family trust...So the wealth of the individual gets assessed, which qualifies them for a Community Services Card and then they wave that around (Pharmacist, $\mathrm{Ph}$ )

Sole supply ${ }^{\mathrm{i}}$ provision raised issues in terms of: supply outages when switching supplier (and having to pay for

\footnotetext{
${ }^{\text {i }}$ Sole supply arrangements are likely to be used by PHARMAC in markets where generic competition exists, resulting in there being only one brand of a particular chemical listed. It is possible that PHARMAC would agree preferred supplier status for some chemicals in exchange for price concessions, affecting access to related pharmaceuticals within the same therapeutic group. Pharmaceutical Management Agency proposed pricing strategy initiatives-sole supply arrangements. Pharmaceutical Management Agency; 2002 [cited]. Available from: http://www.pharmac.govt.nz/2002/07/19/nhps.pdf.
} 
- By whom and how are decisions made?

- Poor medicines policy awareness

- Poor health literacy; impacting timing of presentation and medicines adherence

- Access to prescribers; physical timing and affordability

- Socioeconomic factors (encompassing rural residents)

- Sole supply; out of stock vulnerability and cost, options for intolerance

Discord in recommendations between PTAC and subcommittees

- Access challenges on the ability to pay for litigation; non-medical person then decides access

Lack of health impact monitoring

- Need for integrated electronic patient records, prescribing information and PHARMAC schedule

- Efficiency is static; needs to move towards increases in therapeutic benefit manufacturing requirements constraining for low demand medicines

- Increasing demand and cost of medicines impacting affordability

- Need for clinical expertise and New Zealand specific research management
- Registration, evidence and

- Need for better medicines

- Socioeconomic factors

- Need to use 'Health Equity Assessment Tool' to assess policy and inequities/ inequalities

- Higher burden of disease for Māori and Pacifica; needing risk factor lens

Lacking proper engagement at times

- Cultural competency

Use of complementary medicine

- Need to capture ethnicity statistics in new initiatives
Very powerful position of provision; will they cope with role expansion?

- Young inexperienced staff and high attrition rate

- What health outcomes are being measured?

- Is the lost health opportunity being measured?

- Budget too small; need higher percentage of health budget; 'Vote Health'

- Cost driving value and causing delays

- Need to move to dynamic efficiency

- Need analytical framework to compare all health technologies

- Submission process inefficient

- Economic evaluation influencing therapeutic value evaluation; need to be separated

- Questionable how well health professionals understand pharmacoeconomic modelling

- In-house economic variables are not necessarily consistent with standard practice or PHARMAC's requirements of suppliers

- Hard for suppliers to understand outcome or evaluation process when variables changed

- Website very informative but hard to navigate

- Concern with expansion into hospitals and limiting choice in acute care and moribund disease setting

- Sustainability of current access with increasing demand

- Affordability of a panacea
- Many unfamiliar and sceptical of the benefits and who gets them vs the trade offs

- New Zealand, a small country that needs trade partners

- Where will the financial cost be felt and how will it be dealt with?

- Will there be an increase in the cost of provision?

- A lot of money is being spent on health already and the benefits are low

- Australia lost a lot with their agreement with the USA; we should learn from it

- America's influence is reducing and other forms of protection may evolve

- Patent extensions will delay generic entry and raise costs

- Will the pharmaceutical industry have a greater influence on supply?

- Access to new medicines may improve

- Sovereignty of choice; will there be increased public appeals and litigation?

-What does transparency mean and does it 'cut both ways'?

- PHARMAC's monopsony is an anathema to the USA

- NZ pharmaceutical representative educating 'sister' organisation in NZ system

- Once a medicine is registered for use, it can be prescribed PHARMAC may choose to not fund it
Special Authority access unnecessary once appropriate prescribing established

- Need to differentiate high cost vs highly specialised need and cost

- NPPA access scheme brings equitable access for oncology but too early to assess

- NPPA capturing patient sub-type classification

- NPPA process inefficient and consuming valuable specialist time

- Limits access due to cost; but about collective good and who pays

- Access cheaper in other countries?

- Pharmaceutical companies have good profit margins

- Oncology stigma that everyone dies but differences in survival seen at the margins

- Evidence does not meet PHARMAC's evaluation criteria

- Constraints of 'rule of rescue' vs utilitarian provision

HCM, High Cost Medicines; NPPA, Named Patient Pharmaceutical Assessment; NZ, New Zealand; PHARMAC, Pharmaceutical Management Agency; PTAC, Pharmacology and Therapeutics

Advisory Committee; TPPA, Trans Pacific Partnership Agreement.

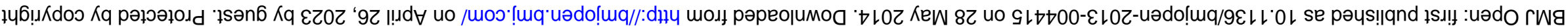


the alternative option) options for patient intolerance and vulnerability if a significant disruption in supply occurs (eg, a disaster destroying a supplier's warehouse).

There was an additional reference to policies and funding needing to be consistent and interlinked, especially for priority areas. 'Quit-Line' was given as an example: a NZ $\$ 40$ million funded smoking cessation programme, described as having markedly less evidence than the appropriate medicines (which were not funded for many years). Budgetary constraints were the reason given for this. Equally, the government funding of 'alternative medicines' was described as something which needed a debate:

...government is providing funding for people to obtain alternative medicines...real debate to be had...money better spent some place else in the healthcare system? (Pharmceutical Industry, PI)

One doctor voiced frustration at PHARMAC's Pharmacology and Therapeutics Advisory Committee $(\mathrm{PTAC})^{\text {ii }}$ being 'generalists' who override the recommendation of their subcommittee. With patient subtyping and genomic medicine on the horizon, he considered that 'generalists' may not understand what they are assessing and dismiss research, thereby inhibiting access. Access is then through an ability to pay for litigation and decided by a non-medical expert.

With demographic changes increasing the demand for healthcare services and a general movement towards increasing costs of new medicines, there was concern for future affordability of medicines. It was suggested that funding may move away from being population based and move towards funding health outcomes. An academic suggested that changes in copayments, taxation or medicines classification status may result. The oncologist had concerns that the lack of research (research being an attracter) being conducted within New Zealand will compound the low availability of future medical specialist prescribers. Extending prescribing ability to non-doctors was considered a help. However, for oncology, a medical specialist was still considered to be required to make treatment decisions.

\section{Ethnicity issues}

Most of the issues presented related to socioeconomic variables and are presented under General Medicines Policy Issues.

Those with poor English speaking skills were described as having access to an English speaking relative or even interpreters if needed:

I think if they can access General Practice or the Hospital system, their access to the medications is just as

iiPTAC is PHARMAC's primary clinical advisory committee. PTAC's role is to provide clinical advice to the Board of PHARMAC. good as anybody else's. I'm not aware of any specific ethnic problems in accessing our medicines... (GP)

One GP felt strongly that Māori and Pacifica access inequities are evident and are resulting in poorer health outcomes. He believes his colleagues are treating everyone the same but with inequitable risk: earlier intervention, improved communication, education and patient engagement are required:

I think the key issue is the prescribers have a poor understanding of inequalities. Because, the prescribers generally approach things as; I treat everyone the same...they must have an inequity lens on anyone they see...but if the quality of your discussion and the quality in the way in which you prescribed that was poor i.e., you culturally are incompetent and you have a disconnect with the patient... (GP)

Other issues related to Asian ethnicities wanting treatment (oncology setting) irrespective of the likely outcomes and the use of alternative treatments, for example, St John's Wort or vitamin C injections impacting on medical treatment. One of the doctors had issues with alternative practitioners recommending such treatments.

\section{Pharmaceutical Management Agency}

There was general appreciation shown towards PHARMAC's strategy of creating competition in order to achieve a lower purchasing price. This was seen as advantageous for the purchase of a greater range of medicines, in the context of a fixed budget.

The budget was defined as the threshold for provision, which was considered too small by an academic and pharmaceutical industry stakeholder, causing a focus on cost as the driver of value and provision, thereby contributing towards 'static efficiency':

If Pharmac's objective is to stay within budget then it's doing well...improve the health of New Zealanders within a capped pharmaceuticals budget...it's doing moderately well...objective were to improve the health of New Zealanders taking into account the financial constraints of Vote Health...it's doing poorly because it should be fighting for a better share of Vote Health (Ac)

A public service (PS) stakeholder offered the following standpoint: 'You can always achieve more with more' (in terms of a bigger budget), but an analytical framework is not in place that would define whether the medicines budget receives a fair proportion of 'Vote Health' or not.

PHARMAC's budget is determined at regularly defined intervals but medicines enter the marketplace sporadically. This has resulted in concerns from oncologists who believe that extra funding may not be available to cater the needs of patients.

The Private Health Care Organisation (PHCO) stakeholder thought PHARMAC's approach of requiring new 
and more expensive medicines to be better than standard medicines a 'completely acceptable approach'. It was suggested by the PHCO and an academic that their approach could be more widely adopted, both overseas and with the expansion of PHARMAC's role to medical devices:

...the expertise PHARMAC has built up...is something that we could learn from and borrow from, for the wider health sector...I'd like to see them take on medical devices, because that is absolutely scandalous that these products are getting onto the market without being properly evaluated... (Ac)

There was caution given by one pharmacist that PHARMAC's expansion into hospital medicines (in an acute care setting of moribund disease) may limit choices. Concern was shown for risk, if New Zealand is leading the world in this type of provision.

Provision was described as having a utilitarian focus: 'The greatest good for the greatest number' (PS) and described as being: you get what you need-not what you want. One doctor questioned whether the lost opportunity from not treating someone is being measured. Rare disorder patients were mentioned and are discussed under High Cost Medicines. The distinction was made that provision of a medicine in a cost-effective manner, which PHARMAC achieves, is not the same as delivering healthcare:

I find some of their PR a little bit irritating...bray on about the marvellous healthcare they're delivering...delivering medicines in a cost effective manner but that's not saying it's delivering healthcare... (PHCO)

Questioning PHARMAC's undertaking of economic modelling received very favourable comments from 15 of the participants. Three participants were not familiar with economic modelling:

I think it's world leading actually. No one else dares do it. That's the crazy thing. Here we are little old New Zealand and we dare do it (Ac)

Well I mean, as a tax payer you could argue that for the majority of the products they get in, they've done a really good job of driving cost out of the system (PI)

Technically it's very good. PHARMAC considers clinical effectiveness and cost effectiveness...they make tradeoffs...they look at the QALYs and the number of people affected and how their quality of life will be improved and so on, I think is a very good model (PS)

It was suggested that the cost-benefit of returning an individual to their normal daily activities should be considered by PHARMAC, such as what Accident Compensation Corporation does when assessing intervention options.
A pharmaceutical industry stakeholder and academic were concerned that the required economic modelling submitted by suppliers is adjusted with unknown 'in-house' variables, making it hard for suppliers to understand decisions. This was contrasted against Medsafe's practice, where decision modelling is transparent:

Pharmac receives a dossier from the company... Assumptions of statistical models get changed...QALYs get changed...population who will use the product get changed...that should be part of a scientific debate... companies don't know what information is being used to make the decisions on their products...we would like a right of reply to those...It happens with MedSafe... Not as though it could potentially negatively affect evidence based decisions (PI)

Delays in the submission process of up to 8 years, described as a 'medicines waiting list', were a matter of concern for an academic, pharmaceutical industry stakeholder and PGR, all of whom thought access was related to cost. There was a suggestion from one academic to follow Australia's submission process and outsource assessments from independent bodies.

\section{Trans Pacific Partnership Agreement}

Very few participants were familiar with the TPPA, which some referred to as speculation and no facts. One participant refused to make any comments related to the TPPA.

There was acknowledgement that trade deals are complex and often require compromises and trade-offs. New Zealand was referred to as a 'small country' and 'we need our trade partners'. There was concern that already 'big amounts' are being spent on healthcare and the 'benefits are low' and if there is a resultant increase in the cost of medicines, where would resources come from to offset any cost increases.

The main issues were: (1) patent extension, delaying generic entry into the market, thereby prolonging a higher cost of provision; (2) industry influencing supply (described as an issue of sovereignty) may result not only in quicker access to new medicines, but also in an increase in public campaigns and appeal processes if PHARMAC's decisions are unpopular with the pharmaceutical industry or patient groups; and (3) transparency requests in PHARMAC's assessment process caused the most concern and confusion. One academic said he did not think PHARMAC could be more transparent and that transparency might mean the industry discloses its pricing processes and the results of all clinical trials.

In general, scepticism was voiced as to what the driving force is behind the agreement and what the benefits would be for New Zealand-with the USA being a protected market (heavily subsidised). Australia was described by a pharmaceutical industry representative as getting 'trounced' over their agreement with the USA, 
losing a lot of their pharmaceutical production and jobs as a result:

Forget it...wouldn't even bother going along to the negotiations $(\mathrm{PHCO})$;

...tell the US to bugger off quite frankly. You either put everything on the table and we talk about it or no, you don't...We should learn from what happened in Australia... (PI)

Conversely, another participant suggested that while 'America' has influence, it may become limited as a result of the influence of China's developing economy and differing ideas around protection and new opportunities may develop:

...a hugely developing economy in the form of China that basically has total disregard for such things...so the ability for America...is probably going to be limited in the world of the future, and maybe different forms of protection of ideas will kind of evolve...it's very hard to predict how the market might respond or what kind of new opportunities develop (PS)

A pharmaceutical industry stakeholder said Medicines New Zealand (New Zealand's prescription medicines representative association, same title as the policy) is attempting to ensure that its USA equivalent understands New Zealand's medicines system:

\begin{abstract}
...working quite hard to ensure...our sister organisation in the US is effectively asking the US government to achieve out of the process, is well enough informed to understand actually what the New Zealand model does achieve, what it doesn't achieve and how that can be improved...So we're working hard to make sure it's a process that actually benefits New Zealanders as well, and all of the transparency, timeliness, appeals-those aspects that we've discussed, are exactly I think what the US is likely to be asking for (PI)
\end{abstract}

Most considered that New Zealand's current ability to access generic medicines or independence in procuring medicines should be upheld. If not, funds may need to be redirected from other services or patient copayments would need to rise, in order to compensate a likely increase in the cost of medicines.

\section{High-cost medicines}

A GP questioned the necessity of continuing the Special Authority (SA) ${ }^{\text {iii }}$ status for a medicine once the appropriate use of a medicine has been established. Not all participants were familiar with the Named Patient

\footnotetext{
${ }^{\text {iii }}$ A criteria define the clinical circumstances of patients who can receive funding for the medicine. People may first be required to try a less expensive medicine or the medicine may need to be prescribed by a particular type of health practitioner.
}

Pharmaceutical Assessment (NPPA) ${ }^{\text {iv }}$ access scheme. Most high-cost medicines were described as being 'breakthrough' or 'expensive' and are restricted, to control spending. One participant said, if it was 'dirt cheap', there would be 'no argument', indicating the case even if the medicine did not have clear health benefits:

My bet, is that PHARMAC would listen to anyone that agrees with them saying no. Because it's expensive... They are diametrically opposed for a reason and the reason is cost $(\mathrm{Ph})$

The Rabbits in charge of the lettuce patch (M)

One PS stakeholder thought there to be no inappropriate blocking of access to medicines, as no complaints about access had been received at their level. Equally, another PS stakeholder commented that there are patients accessing medication costing up to NZ $\$ 500$ 000/year:

...So it's not that the system can't cope with treatments that are high cost, it's just that we would expect a return for that cost and for it to be justifiable in terms of what we value (PS)

A small group of patients were described as not having access to high-cost medicines. Access was described as 'the collective good'. On the other hand, 'people dying from a lack of access to very cheap and simple therapies' was described. It was suggested that it is DHB's remit to look after its population. A statement was made if we are advocating treatment at any cost:

It's a question of who pays for all these things. I think if you have pretence; like there is in the USA, that cost isn't of any relevance...then you're going down the wrong path (PHCP)

The oncologist described the NPPA process as inefficient and that a comprehensive and referenced application takes him up to $6 \mathrm{~h}$, potentially impacting on his clinic time and perversely hindering patient access. He suggested PHARMAC at a nominal cost could employ someone to aid in information gathering and, in the process, develop expertise.

Additionally, the oncologist believes oncology has the stigma that everyone dies but individual survival may be greater than the median survival assessment. This issue was presented in comparing the availability of two to three drugs in Australia that are unavailable in New Zealand.

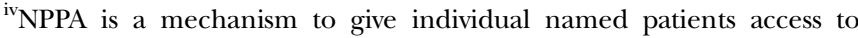
medicines they need, but which are not funded on the Pharmaceutical Schedule. NPPA replaces the three Exceptional Circumstances (EC) schemes that PHARMAC previously managed. 
Questions were posed: (1) is it fair to give fourth-line or fifth-line chemotherapy and not give a first-line treatment, for example, for rare disorders? and (2) when should one stop the treatment? A patient was described as gaining access to expensive medication; however, their condition was fragile and they died a few weeks later:

I think it's important if Pharmac has a few loose strings in terms of hospital and severe rare conditions. They are perhaps because of how they are funded, they want a very narrow perspective on those, to try and avoid blow out. They are very emotive issues we don't always know how to best manage people's care $(\mathrm{Ph})$

High need patients, such as rare disorder patients, received the most sympathy for difficulty in access because of the exclusion criteria. Evidence requirements were described as difficult to attain due to the low patient numbers. Conversely, the PHCO suggested that the supplier needs to produce quality evidence:

...where there's some evidence, but not solid or quality evidence:...the company doing the-providing the medication, it behoves on them to do some research in those areas and produce quality data (PHCO)

\section{DISCUSSION}

We purposefully attempted to be open to issues and their capture, despite some issues already being identified. Our focus was on access to medicines. It is possible that there are other issues in existence that we neither recognised nor captured. We did not seek to determine issues specifically related to generic medicines, considered a 'vital component of New Zealand's medicine cost management policies' by Babar et al. ${ }^{12}$

\section{Medicines policy}

Medicines are clearly valued health interventionsevidenced by the budget, literature and responses from stakeholders. The smaller percentage spent on pharmaceuticals in New Zealand (described as a constrained budget), compared with similar countries such as Australia, the UK and the USA, ${ }^{2}$ may in fact reflect the price reduction strategies that are implemented by PHARMAC, ${ }^{32}$ as opposed to less opportunity to improve health outcomes. However, this needs to be tested through robust research on health outcomes and their relationship to pharmaceutical spending.

Delayed access and the resultant impact discussed by some of the participants was also described by Ellis and Hamer, ${ }^{33}$ in relation to New Zealand's statin availability for atherosclerotic patients, as probably negatively impacting the health outcome and considered to be due to the capped budget. They considered this as 'anomalous', as other types of healthcare are not capped. This anomaly was also described by a number of participants but may change with PHARMAC's expanding role.
New medicines are increasing in cost, along with demand, causing tension in affordability. Price efficiency initiatives, such as what PHARMAC encourages, help ease the tension in affordability of provision. Another option is to reduce demand, either through 'gate keeping' (not usually a popular choice) or genuine effects, such as initiatives to maintain health or prevent disease. We assume that a reduction in demand and therefore burden of provision should result in healthcare becoming more affordable for providers and helping those remaining in need.

Manning $^{34}$ compared the processes of decisions, pricing, economic analysis, provision and access and participation and appeals between the UK, Australia and New Zealand. It was suggested that resolving issues may benefit from a disputes panel comprising a broad range of experts in scientific, economic, policy and ethical evaluations, in order to provide an objective decision. Manning additionally reported that approximately onesixth of the UK's National Institute for Healthcare and Care Excellence (NICE) recommendations are appealed and upheld. ${ }^{35}$ There should not be great demand if the evaluation processes are robust.

\section{Ethnicity}

Our participants revealed that low socioeconomically related populations (encompassing Māori and Pacifica people) are continuing to have access issues related to financial, structural, educational and cultural barriers. These findings were consistent with that of Jatrana et $a l^{36}{ }^{36}$ who assessed SOFIE-health's 18320 respondents (an add-on to Statistics New Zealand's longitudinal survey of Family, Income and Employment). Māori and Pacific people were more likely to defer purchasing a prescription due to cost, which at that time was NZ $\$ 15$.

Māori represent approximately $15 \%$ of New Zealand's population $^{37}$ and on average have the poorest health status of any ethnic group in New Zealand. ${ }^{38} 39$ Pacifica people represent $6.5 \%$ of the population and also experience health inequalities. He Korowai Oranga: the Māori Health Strategy (2002) ${ }^{38}$ recognises the Treaty of Waitangi principles of: partnership, participation and protection, through which the aim is to reduce the existing health inequalities. This aim is extended to include the Pacific people, who like Māori are over-represented by a low socioeconomic situation, reflecting low affordability and health literacy, which in turn affects access. The Ministry of Health recently launched SIA $^{40}$ an additional targeted capitation payment, available to primary healthcare organisations to reduce health inequalities. It is designed for new services (eg, outreach programmes) or improving access (eg, funding transport) for Māori, Pacific people and those of low socioeconomic status. Once SIA is embedded, it would be prudent to evaluate its impact.

Other Ministry of Health initiatives, such as Whanau Ora (to build the health, participation and capability of families) and One Heart Many Lives (to improve the 
cardiac health of Māori and Pacific men) along with recent changes in health practitioner training, appear to be good initiatives for engaging Māori and Pacifica in a culturally appropriate way. It would be prudent to evaluate their impact.

We did not have any issues specifically described for new immigrants. It was described to us that patients with poor English speaking capability present to practitioners with an English speaking person, or frequent a surgery of their ethnicity. This is at odds with Babar et $a l,{ }^{9}$ who found for 11 Chinese and Indian migrants, residing in New Zealand for less than 5 years, that financial barriers existed in affording doctors, pharmacists and medicines, and that language barriers exist. This anomaly may highlight the differences in the perspective and experience of the stakeholders we interviewed.

Asia and India have different medicines access systems to New Zealand. Babar et al additionally found that there is a lack of information on New Zealand's medicines system, including medicines provision and classification. The United Nations and World Health Organisations, when discussing the right to health, ${ }^{41}$ refer to migrants as being vulnerable to reduced access to health services for reasons that include language or cultural barriers. New Zealand has a significant migrant population, reported as 927000 in $2006 .^{42}$ The current main countries for immigration are: China $(15 \%)$, the UK (unspecified), India (13\%) and the Philippines $(8 \%) .{ }^{42}$ In consideration of Babar et al s work and immigration statistics, there may be a significant number of people from these countries with issues, resulting in difficulties in accessing healthcare and therefore medicines. ${ }^{8-10}$ In the light of this, it may be worth investigating new immigrant issues further.

\section{PHARIMAC}

The general appreciation for New Zealand needing to be efficient, in order to provide more medicines, expressed by our stakeholders was also shown by Ragupathy et $a l .{ }^{26}$ Included was the need to apply consistent economic evaluations to other health technologies, to support congruous decisions for resource allocation. PHARMAC's expansion into procuring hospital medicines and medical devices may enable greater consistency of evaluation across technologies.

The significance of PHARMAC's role expansion should not be underestimated. PHARMAC will need to exercise caution when expanding its role into hospitals, which are generally settings of acute and moribund disease. We are unaware whether a closed formulary has occurred elsewhere in the world. PHARMAC has been noted to have consulted directly with medical specialist groups to discuss their role expansion, including consultation on hospital medical devices, ${ }^{43}$ so it would appear to be fully cognisant and appreciative of this issue.

We found delays of up to 8 years in PHARMAC's process for funding medicines onto the Pharmaceutical Schedule, which a number of our participants purported to be due to the medicine's pricing and/or PHARMAC's budget not being able to expand. Other reasons may be the medicine's priority status, insufficient information or not meeting PHARMAC's nine decision criteria. ${ }^{44}$ The question is whether this means delays in therapeutic advancement and therefore improved health outcomes.

The measurement of opportunity foregone was of clear concern to the oncologist we interviewed. New Zealand has a capped medicines budget; it cannot expand and therefore drives the need for efficient spending (determined using cost utility analysis, where medicines are assessed against QALY gains per $\mathrm{NZ} \$ 1$ million). Using this process for provision means there is opportunity foregone, as described by Milne and Wonder. ${ }^{14}$ We are not aware of New Zealand focused research assessing either opportunities foregone or other specialist viewpoints on access, the exceptions being: Ellis and Hamer ${ }^{33}$, discussing the delayed availability of cardiac medicines; MacCormack $e t a l^{31}$ in 2009, assessing stakeholders' views on needed access to highcost medicines and the Sage report for the Ministry of Health in $2010,{ }^{22}$ reporting the consultation of stakeholders on the proposal to expand PHARMAC's role.

Sole supply issues (supply outages, lack of palatable formulations, resultant out-of-pocket payments for alternatives and vulnerability as a result of a disaster) were reported to be continuing, despite there being penalties for suppliers. This was also reported by Babar et $a l^{45}$ who reported additional concerns with poor quality products in the past, from previous studies.

\section{Trans Pacific Partnership Agreement}

There is very little information available on the TPPA; the reason given is, particulars of the negotiation are changing. What does exist concurs with our findings; it questions the motivation and self-interest of parties involved and warns of possibly binding impacts that may affect health services budgets and PHARMAC's autonomy, including method of procurement and provision. ${ }^{25-29}{ }^{46}$ Such impacts stem from the USA's desire for stricter protection of intellectual property rights, transparency of in-house evaluation, regulatory coherence, dispute settlement, government procurement and evidence-based decisions being contestable in court. Unless budgets expand to cope with likely increases in costs, there may need to be a re-evaluation of provision, subsidies and copayments. In contrast to existing publications, our research additionally suggested that a TPPA may enable earlier access to newer medicines. It may be of use to quantify what effect a TPPA would have on medicines access.

\section{High-cost medicines}

A significant issue discussed in our study was the need to differentiate between high-cost medicines and highly specialised needs and medicines in relation to the NPPA access scheme. McCormack et $a \hat{l}^{11}$ suggest that a 
medicine that costs $\mathrm{NZ} \$ 20000$ per patient per year may be considered high cost. It is important to be cognisant of the total cost to the health system of any medicine, which is dependent on the number of patients treated (volume used) and the acquisition price. Some high-cost medicines may not result in a high total cost to PHARMAC, for some patient groups. Gallego et $a t^{47}$ question how treating large populations at high total cost for small population gains compares with treating smaller populations, for possibly significant benefit.

The issue of treating large versus small populations may intensify with patient subtyping and genomic medicines development (as described by the oncologist) where greater expectation to fund (ie, demand) may occur. With the NPPA process now reported in our findings as enabling the capturing of patients with cancer subtype information, cancer medicine outcomes may become easier to measure and, if positive, make it harder to decline funding treatments. It may also mean the table is turned and large populations end up having limited treatment options, if outcomes cannot be measured in the same way. However, funding outcomes will give a clear indication for innovation and direction to suppliers and funders of medicines.

Our findings describe the SA and the NPPA access schemes as being inefficient. The SA inefficiency finding is also supported by Babar et $a l \mathrm{~s}^{45}$ evaluation of GP perceptions on access to medicines in New Zealand. Once correct prescribing of a medicine has been established, it may not be necessary to continue a medicine's SA status. The NPPA process appears to impact significantly on consultant clinic time, which may perversely hinder patient access. With demographic trends indicating greater demand for such medicines, the impact of the inefficiency may intensify. PHARMAC's website lists 555 approvals and 15 declines for NPPA access. ${ }^{48}$ The high rate of NPPA approvals brings into question the need for such a process. Alternatively, it may be more efficient for PHARMAC, at a nominal cost, to contract an evidence-based facilitator, to ease the burden of application for clinicians.

Difficulty in access to high-cost medicines, encompassing rare disorder patients, as described by our participants, has been widely documented. ${ }^{31} \quad 47 \quad 49-58$ The nature of rare diseases makes it hard to gain the necessary evidence PHARMAC requires for evaluation. This issue is compounded for suppliers because the need to satisfy manufacturer ordering and regulatory requirements adds to the unit cost of supply for low-volume demand medicines. It may be worth investigating options to reduce cost of supply and provision in the context of constrained evidence. PHARMAC has recently sought public and professional input into its decision criteria. The results have yet to be published but may reveal new options or initiatives.

Our research highlighted the issue of access to medicines of therapeutic value in the context of a fixed predetermined budget and the difficulties in how priorities for funding are determined. Lu et al, ${ }^{59}$ discussed the ethical perspectives and access to high cost medicines outlining that ethical aspects could help to achieve the fairest outcomes for individual patients, as well as for the community. This does come with ethical concerns but may enable access and capturing evidence. MacCormack et $a \vec{l}^{31}$ suggest 'risk sharing' supply to ensure some form of access (defining a threshold for maximum numbers to treat for a high-cost medicine above which the supplier funds)

Conversely, Simoens et $a \tilde{l}^{2}$ caution providing access to medicines with limited effectiveness, implying that rare disorders health improvement is more valuable than a common disease, which challenges the utilitarian view that the health gain of each patient is valued equally. With increasing effort in the development and availability of orphan drugs, this issue may only worsen. Equally, other questions arise: because we see that ill health cannot mean preferential treatment over someone who has a 'silent' state of declining health. There are people not getting access to inexpensive medicines, who are at risk, as stated by an academic. Perhaps remedying issues of access based on need could start with prioritising based on the impact of an unmet need?

\section{CONCLUSION}

Overall, despite issues being identified, there was reasonable satisfaction with New Zealand's medicines policy and its principles. In particular, that provision is evidence based, cost effective and there is equitable ability to have prescribed medicines listed as subsidised, on PHARMAC's schedule.

However, despite this, there appear to be some patient groups still experiencing difficulties in access, not necessarily appearing as a result of medicines policy or PHARMAC, such groups being rare disorders and the low socioeconomic (encompassing the rural, Māori and Pacifica populations). Other issues ranged from: the pharmaceutical industry's pricing of new medicines; manufacturer and registration requirements; the submission for funding process; increasing demand for medicines and the resultant financial impact; budgetary constraints; cultural and health literacy; patient affordability and access to prescribers; through to knowledge development for clinical expertise and the measurement of health outcomes.

Our study has highlighted issues in access based on need and the consequences of unmet need, the context being that a fixed and predetermined budget, increasing demand and rising cost of medicines are all compounding constraints in affordability. We suggest that these issues and consequences of unmet needs may worsen and options for demand and provision may need to be explored further.

Contributors ZB conceptualised and designed the study. The data collection, entry and analysis was handled by SF and ZB. SF and ZB wrote the 
manuscript. The final version is approved by both authors. ZB acts as an overall guarantor to this study.

Funding The funding was received from the University of Auckland, funding number $3701346 / 9817$. SF worked as a paid researcher.

\section{Competing interests None.}

Ethics approval Ethics approval was obtained from The University of Auckland, Ethics Committee. Approval number; 8367.

Provenance and peer review Not commissioned; externally peer reviewed.

Data sharing statement The original data are available from the principal author (ZB).

Open Access This is an Open Access article distributed in accordance with the Creative Commons Attribution Non Commercial (CC BY-NC 3.0) license, which permits others to distribute, remix, adapt, build upon this work noncommercially, and license their derivative works on different terms, provided the original work is properly cited and the use is non-commercial. See: http:// creativecommons.org/licenses/by-nc/3.0/

\section{REFERENCES}

1. Statistics New Zealand. Top statistics. 2013 (cited). http://www.stats. govt.nz/browse_for_stats/snapshots-of-nz/top-statistics.aspx

2. Organisation for Economic Co-operation and Development Countries. OECD health data 2013 - frequently requested data: health expenditure. 2013 (cited). http://www.oecd.org/els/ health-systems/oecdhealthdata2013-frequentlyrequesteddata.htm

3. Ministry of Health. Funding. Ministry of Health; 2013 (cited 2013). http://www.health.govt.nz/new-zealand-health-system/funding

4. Pharmaceutical Management Agency. Setting and managaing the combined pharmaceutical budget (CPB). New Zealand Government, 2013 (updated 2013; cited 2013). http://www.pharmac.health.nz/ ckeditor_assets/attachments/381/infosheet-08-community-pharmbudget-2013.pdf

5. Pharmaceutical Management Agency. PHARMAC and hospital medical devices. 2013 (cited). http://www.pharmac.health.nz/ medicines/hospital-devices/

6. Pharmaceutical Management Agency. New Zealand Pharmaceutical Schedule. 2013 (updated April, 2013; cited 2013). http://www. pharmac.govt.nz/2013/04/03/Sched.pdf

7. Associate Minister of Health, Minister of Health. Medicines New Zealand: contributing to good health outcome for all New Zealanders. In: Health MO. ed. Wellington, New Zealand: Ministry of Health, Wellington, New Zealand, 2007:1-17. http://www.pharmac. health.nz/assets/moh-medicines-nz.pdf

8. DeSouza R, Garret N. Access issues for Chinese people in New Zealand final report. Auckland: Auckland University of Technology. 2005. (Contract.)

9. Babar ZUD, Pengelly K, Scahill SL, et al. Migrant health in New Zealand: exploring issues concerning medicines access and use. $J$ Pharm Health Services Res 2013:4:41-9.

10. Suin T. An Holistic Approach to Asian Health Fourth International Asian Health and Well-Being Conference; 2010, Auckland.

11. Ragupathy $\mathrm{R}$, Aaltonen $\mathrm{K}$, Tordoff $\mathrm{J}$, et al. A 3-dimensional view of access to licensed and subsidized medicines under single-payer systems in the US, the UK, Australia and New Zealand. PharmacoEconomics 2012;30:1051-65.

12. Babar ZUD, Grover P, Stewart J, et al. Evaluating pharmacists views, knowledge, and perception regarding generic medicines in New Zealand. Res Soc Adm Pharm 2011:7:294-305.

13. Wonder M, Milne R. Access to new medicines in New Zealand compared to Australia. N Z Med J 2011;124:12-28.

14. Milne R, Wonder M. Response to PHARMAC on access to new medicines in New Zealand compared to Australia. N Z Med J 2011;124:18.

15. Tordoff JM, Norris PT, Reith DM. 'Price management' and its impact on hospital pharmaceutical expenditure and the availability of medicines in New Zealand hospitals. Value Health 2008;11: 1214-26.

16. Aaltonen $\mathrm{K}$, Ragupathy $\mathrm{R}$, Tordoff $\mathrm{J}$, et al. The impact of pharmaceutical cost containment policies on the range of medicines available and subsidized in Finland and New Zealand. Value Health 2010;13:148-56.

17. Cumming J, Mays N, Daubé J. How New Zealand has contained expenditure on drugs. BMJ (Online) 2010;340:1224-7.
18. Metcalfe S, Grocott R. Comments on 'simoens, s. health economic assessment: A methodological primer. int. j. environ. res. public health 2009, 6, 2950-2966'-New Zealand in fact has no cost-effectiveness threshold. Int $J$ Environ Res Public Health 2010;7:1831-4

19. Moodie $\mathrm{P}$, Metcalfe S, Poynton M. Do pharmaceutical score cards give us the answers we seek? N Z Med J 2011;124:69-74.

20. Moodie P, Metcalfe S, McNee W. Response from PHARMAC: difficult choices. N Z Med J 2003;116.

21. Grocott R. Applying programme budgeting marginal analysis in the health sector: 12 years of experience. Expert Rev Pharmacoecon Outcomes Res 2009;9:181-7.

22. Sage D. Report on the consultation period for the proposal to expand the functions of PHARMAC. 2010. (Contract.)

23. Morgan S, Boothe K. Prescription drug subsidies in Australia and New Zealand. Aust Prescriber 2010;33:2-4.

24. Carlson JJ, Sullivan SD, Garrison LP, et al. Linking payment to health outcomes: a taxonomy and examination of performance-based reimbursement schemes between healthcare payers and manufacturers. Health Policy 2010;96:179-90.

25. Gleeson D, Lopert R, Reid P. How the Trans Pacific Partnership Agreement could undermine PHARMAC and threaten access to affordable medicines and health equity in New Zealand. Health Policy 2013;112:227-33.

26. Ragupathy $\mathrm{R}$, Tordoff $\mathrm{J}$, Norris $\mathrm{P}$, et al. Key informants' perceptions of how Pharmac operates in New Zealand. Int J Technol Assess Health Care 2012;28:367-73.

27. Moynihan R. New Zealand agency comes under pressure to pay more for drugs. BMJ 2011;342:d3933.

28. Foster RH, Wilson N. Trans-pacific partnership: will Pharmac become a victim of its own success? BMJ 2011;343:d4908.

29. Faunce TA, Townsend R. The Trans-Pacific Partnership Agreement: challenges for Australian health and medicine policies. Med J Aust 2011;194:83-6.

30. Raftery JP. Paying for costly pharmaceuticals: regulation of new drugs in Australia, England and New Zealand. Med J Aust 2008;188:26-8.

31. McCormack P, Quigley J, Hansen P. Review of access to high-cost, highly specialised medicines in New Zealand. 2010. (Contract.)

32. Pharmaceutical Management Agency. Proposed pricing strategy initiatives-sole supply arrangements. Pharmaceutical Management Agency, 2002 (cited). http://www.pharmac.govt.nz/2002/07/19/nhps.pdf

33. Ellis CJ, Hamer AW. Cardiovascular health in New Zealand: areas of concern and targets for improvement in 2008 and beyond. N Z Med $J$ 2008;121:5-10.

34. Manning J. Priority-setting processes for medicines: the United Kingdom, Australia and New Zealand. J Law Med 2011;18:439-52.

35. National Institute for Health and Care Excellence (cited). http://www. nice.org.uk

36. Jatrana S, Crampton P, Norris P. Ethnic differences in access to prescription medication because of cost in New Zealand. $J$ Epidemiol Community Health 2011;65:454-60.

37. Statistics New Zealand. Māori population estimates. 2012 (cited) http://www.stats.govt.nz/browse_for_stats/population/estimates_and projections/maori-population-estimates.aspx

38. Ministry of Health NZG. He Korowai Oranga: Māori Health Strategy. 2002 (cited). http://www.health.govt.nz/publication/ he-korowai-oranga-maori-health-strategy

39. Ministry of Health NZG. The Health of Māori Adults and Children 2013 [cited]. http://www.health.govt.nz/publication/ health-maori-adults-and-children

40. Ministry of Health NZG. Services to improve access. 2011 (cited) http://www.health.govt.nz/our-work/primary-health-care/ primary-health-care-services-and-projects/services-improve-access

41. The United Nations WHO. The right to health. 2008 (cited). http:// www.who.int/hhr/activities/Right_to_Health_factsheet31.pdf

42. Ministry of Business Innovation and Employment. New Zealand Government. Migration Research (cited). http://dol.govt.nz/research/ migration/monthly-migration-trends/13jun/index.asp

43. Pharmaceutical Management Agency. Adapting the PHARMAC model for medical devices management. 2013.

44. Pharmaceutical Management Agency. Decision criteria Pharmac. 2013 (cited 2013 Nov 4). http://www.pharmac.health.nz/medicines/ how-medicines-are-funded/decision-criteria

45. Babar ZUD, Grover P, Butler R, et al. A qualitative evaluation of general practitioners' perceptions regarding access to medicines in New Zealand. BMJ Open 2012;2:e000518.

46. Kelsey J. Hidden agendas what we need to know about the TPPA BWB texts. 2013 (cited). http://www.bwb.co.nz

47. Gallego G, Taylor SJ, Brien JaE. Funding and access to high cost medicines in public hospitals in Australia: decision-makers' perspectives. Health Policy 2009;92:27-34. 
48. Pharmaceutical Management Agency. NPPA outcome report cumulative for March-December (updated 24/1/13). Pharmaceutical Management Agency, 2013 (cited). http://www.pharmac.health.nz/ ckeditor_assets/attachments/249/summary_of_nppa_decisions dec_12.pdf

49. Forman J, Taruscio D, Llera VA, et al. The need for worldwide policy and action plans for rare diseases. Acta Paediatr Int $J$ Paediatr 2012;101:805-7.

50. Lu CY, Williams K, Day R, et al. Access to high cost drugs in Australia. BMJ 2004;329:415-16.

51. Lee TH, Emanuel EJ. Tier 4 drugs and the fraying of the social compact. N E J Med 2008;359:333-5.

52. Simoens $\mathrm{S}$, Cassiman D, Dooms $\mathrm{M}$, et al. Orphan drugs for rare diseases: is it time to revisit their special market access status? Drugs 2012;72:1437-43.

53. Munoz J, Kurzrock R. Targeted therapy in rare cancers-adopting the orphans. Nat Rev Clin Oncol 2012;9:631-42.
54. Hudson I, Breckenridge A. The challenges of orphan drugs and orphan diseases: real and imagined. Clin Pharmacol Ther 2012;92:151-3.

55. Drummond MF, Wilson DA, Kanavos $\mathrm{P}$, et al. Assessing the economic challenges posed by orphan drugs. Int $J$ Technol Assess Health Care 2007;23:36-42.

56. Joppi R, Bertele V, Garattini S. Orphan drugs, orphan diseases. The first decade of orphan drug legislation in the EU. Eur J Clin Pharmacol 2013;69:1009-24.

57. Largent EA, Pearson SD. Which orphans will find a home? The rule of rescue in resource allocation for rare diseases. Hastings Cent Rep 2012;42:27-34.

58. Cheema PK, Gavura S, Migus M, et al. International variability in the reimbursement of cancer drugs by publically funded drug programs. Curr Oncol 2012;19:e165-76.

59. Lu CY, Macneill P, Williams K, et al. Access to high cost medicines in Australia: ethical perspectives. Austr N Z Health Policy 2008;5:4 